\title{
Verbalization of Knowledge Structures of Spanish Scientific Technical Text
}

\author{
Taisia G. Popova* \\ People's Friendship University of Russia \\ 3 Ordzhonikidze Str., Moscow, 115419, Russia
}

Received 18.11.2016, received in revised form 15.12.2016, accepted 12.01.2017

\begin{abstract}
Integration of the new, the old and the precedent knowledge is determined by the construction of a universal scientific text. New knowledge, verbalized on the text plane is a detailed, compositional voice structure, representing the substantive content of the resulting knowledge. Verbalized new knowledge is the semantic core of all the text in its main phases - the problems, ideas, hypotheses, evidence, conclusion. The old knowledge arises at the intersection of two contexts - "own" and "foreign". The old knowledge demonstrates the history of the problem, solutions to scientific problems, expresses the connection with the previous concepts, the author explicates belonging to this or that scientific school, represents the utterance. Types of textual representation of the old knowledge are defined by cognitive and communicative functions. Verbal markers of the old knowledge introduction are verbs of speech and thought for another's speech.

The precedent knowledge can be considered as one of the mechanisms of formation and preservation of scientific tradition. These are not just signs of entire texts, which are equivalent in meaning and significant personal marks, as indicated by anthroponomy contained therein. The emergence of case contexts in scientific publications testifies anthropomorphization and personification of science, i.e., scientist's name - the subject of a precedent - at some point begins to identify with one's concept, it is included in the "golden fund" of science and becomes a sign of scientific knowledge. In epistemological terms precedent is a typical compression technique of the old knowledge with the purpose of its preservation, compression and further scientific accumulation.
\end{abstract}

Keywords: intertextuality, science text, discourse, new, old and precedent knowledge, discursive markers.

DOI: 10.17516/1997-1370-0010.

Research area: philology.

(C) Siberian Federal University. All rights reserved

* Corresponding author E-mail address: taisapo@mail.ru 


\title{
Verbalizacion del conocimiento del texto español cientifico-tecnico
}

\author{
Taisia G. Popova \\ Universidad Rusa de la Amistad de los Pueblos, \\ Calle Ordzhonikidze, dom. 3, 115419 Moscú, Rusia
}

La integración de la verbalización del conocimiento nuevo, viejo y precedente determina la construcción universal del texto científico - técnico. Se analizan sus funciones, sus marcadores discursivos, se forma el mecanismo de la intertextualidad y la continuidad.

Palabras claves: intertextualidad, texto cientifico, discurso, conocimiento nuevo, conocimiento viejo, conocimiento precedente, marcadores discursivos.

Cada texto representa un tejido nuevo insertado en las citas viejas. (R. Barthes)

\section{Introducción}

El término de "la intertextualidad" apareció en el siglo pasado de las décadas 60 - 70 del siglo XX. El punto de partida para el desarrollo de la teoría de intertextualidad fueron las ideas de M. M. Bakhtin sobre «las voces ajenas» $\mathrm{y}$ «loguismo» y su concepción de la «novela polifónica», donde se revela el fenómeno del diálogo del texto con otros textos anteriores y paralelos en el tiempo (Bakhtin, 1979, p. 434).

En base de estas ideas la investigadora de semiótica J. Kristeva introdujo por primera vez en 1967 el término «intertextualite» en francés. J. Kristeva en el ensayo titulado «Le mot, le dialogue et le roman», consagrado a Bakhtin, expresa que cualquier texto se construye como un mosaico de citas y tiene inclusiones y la transformaciones de otro texto (Kristeva, 1967). Barthes aclara que todo el texto ya es un intertexto. Cada texto representa un tejido nuevo insertado en las citas viejas, los fragmentos de los códigos culturales, las fórmulas, etc. (Barthes, 1989). Las variedades de los términos afines eran la polifonía, el poliloguismo, el dialoguismo, la transposición, la transtexualidad, etc. Pero sólo el término "intertextualidad" se hizo «favorito» en el ámbito universal aunque hasta ahora la acepción de este término es variable. Actualmente el término de la «intertextualidad» es fundamental tanto en el punto de vista literario como en el punto de vista linguístico. Vamos a definir la categoría de la intertextualidad como una relación multidimensional del texto con otros pre-textos por medio del contenido, de las particularidades genéricas, de la estructuración y de la expresión formal (Popova, 2003, p. 115).

La intertextualidad se considera como una propiedad categorial importante del texto científico que realiza la «deshermetización», la «apertura» del texto y la capacidad de hacer contactos con los textos anteriores (pretextos, prototextos) así como una estrategia especial de la contrucción del texto en distintas áreas de la comunicación.

Para interpretar un texto el lector necesita un conocimiento previo que se refiere a diferentes aspectos: los códigos lingüísticos, el uso del lenguaje en relación con distintas prácticas sociales, la situación social en la que el acto discursivo se produce, el mundo exterior.

\section{Situación intertextual en el texto científico - técnico}

Sumergido en la situación de comunicación cualquier caso del «préstamo» del texto ajeno se 
convierte en una situación intertextual que puede ser presentada como un modelo tridimensional. Sus tres componentes del modelo son: 1) el sujeto (autor) que incorpora en su propio texto con préstamo; 2) el texto con un fragmento prestado; 3) el destinatario con el texto del fragmento prestado. Cada uno de los tres componentes de esta situación intertextual se puede analizar en diferentes direcciones.

En definitiva la situación intertextual de la citación de los fragmentos ajenos hace participar por lo menos tres participantes: el autor del texto original, el destinatario (lector) y el autor de la citación y referencia. El autor y el destinatario permite revelar tres aspectos de investigación que son 1) la fuente del préstamo textual o referencia; 2) el objeto del préstamo textual o de la referencia; 3) el modo de la realización del préstamo textual o de la referencia. Los fragmentos prestados o las referencias insertadas en el espacio del texto portador representan el «dialogo» entre el conocimiento nuevo, el conocimiento viejo y el conocimiento precedente.

La idea de que en el texto científico hay sólo un autor o autores (sujetos) es poco probable, puesto que en el discurso científico hay además muchos autores citadores, referenciadores, conceptadores precedentes. La autorización en la comunicación científica se puede definir como un componente conceptual dialógico. La autorización tiene un carácter de intergación distante debido a la aparición de la autorización «ajena».

La autorización del discurso se puede analizar como un fenómeno unidimensional (sujeto), bidimensional (sujeto+destinatario) $\mathrm{y}$ tridimensional (sujeto+citador+destinatario) y multidimensional. Gran cantidad de citas, referencias y menciones de «otros» autores en el discurso científico indican que la cantidad de sus dimensiones en este sentido puede aumentar y la autorización puede obtener un carácter multidimensional (Dolzhich, 2012, p. 94).
Podemos sacar la conclusión que el espacio autoral del texto científico es multidimensional $\mathrm{y}$ tiene una configuración muy compleja $\mathrm{y}$ en definitiva manifiesta su carácter intertextual.

Vamos a analizar el contenido del "continuum" científico. El contenido del conocimiento científico forma el núcleo cognitivo de la concepción del investigador. Este núcleo incluye dos componentes importantes del «continuum» de la ciencia, o sea el conocimiento nuevo del autor (sujeto) y el conocimiento viejo de los sujetos viejos (autores, citadores $\mathrm{y}$ referenciadores) en su enlace intertextual dialéctico.

En el discurso científico este «continuum» se divide en el subtexto (fragmento del sub texto) del conocimiento nuevo, el subtexto del conocimiento viejo y dentro del mismo el subtexto del conocimiento precedente. El subtexto se comprende como una unidad textual bilateral que verbaliza en la superficie textual distintos conceptos (cognitivos, axiológicos, pragmáticos, etc.) de la estructura conceptual del texto científico (Popova, 2003, p. 115). Estos subtextos están relacionados con los principales parámetros extralingüísticos de la actividad congnitiva y manifiestan el contenido típico del texto científico y su verbalización.

El subtexto del conocimiento nuevo comprende la concepción del autor, el planteamiento del problema, las conclusiones y el resumen. El subtexto del conocimiento viejo y el subtexto precedente forman parte de la estructura conceptual del texto científico y representan la continuidad, carácter dialógico e intertextualidad.

\section{Subtexto del conocimiento nuevo}

El subtexto del conocimiento nuevo comprende la concepción del autor, el planteamiento del problema, las conclusiones 
y el resumen. Así, el conocimiento nuevo del planteamiento del autor es:

«El propósito de este trabajo es evaluar algunas de las características principales del acuifero asociado a los yacimientos» (Ingeniería. Ciencias ambientales, № 37, 1998).

«El principal objetivo de este trabajo es lograr la fotobiodegradación de las mezclas preparadas con almidón» (Ingeniería. Ciencias ambientales, № 37, 1998).

«El presente trabajo pretende revisar los diferentes mecanismos descritos» (Interciencia. vol. 26, №10, 2001).

Los marcadores discursivos (del planteamiento del problema) del conocimiento nuevo son: el objetivo es establecer las causas, se pretende investigar el efecto de las propiedades, se pretende, este proyecto tiene como objetivo, el propósito del presente trabajo, el trabajo pretende, el objetivo de la investigación, como una contribución al estudio, programar el estudio con el propósito, etc.

El conocimiento nuevo de las conclusiones y los resultados del autor son:

«A partir de las referencias hechas, es fácil concluir que la investigación sobre el tema se centra, principalmente, en la digitalización» (Boletín informativo GEOS, 2000).

«Los resultados permiten proponer nuevas leyes de atenuación..» (Interciencia, vol.26, №10, 2001).

«Los resultados del modelo permitieron analizar el funcionamiento...» (Interciencia. vol. 26, №10, 2001).

"Con estos resultados se elaboraron otras pruebas...” (Interciencia. vol. 30, №10, 2001).

Los marcadores discursivos del conocimiento nuevo de las conclusiones y resultados son: es conveniente puntualizar las siguientes conclusiones, los resultados reportados indican, con base en los resultados se puede concluir, los resultados obtenidos nos conducen a, los resultados permiten se concluye que, en conclusión, para concluir, las principales conclusiones se resumen, se determinó que, con la base de los resultados obtenidos se encontró, etc.

El desarrollo del conocimiento nuevo se forma de las etapas básicas de la actividad cognitiva tomando en consideración el contenido de las etapas ((problemas, explicaciones, ideas, argumentos, resúmenes,etc.).

\section{Subtexto del conocimiento viejo}

El subtexto del conocimiento viejo (anterior) establece la concepción del autor con las ideas de los investigadores anteriores, desarrollando las relaciones intertextuales. Por ejemplo:

"Los ingenieros especializados en la mecánica y dinámica de suelos, conocen que el suelo en la naturaleza se presenta con múltiples características que dependen de su origen y formación en el ambiente de la región» (Ingeniería. Investigación y tecnología. 2002).

Los marcadores discursivos del conocimiento viejo son: de acuerdo con, según tal o cual persona, según la definición, a juicio de, en autores como, etc.:

"A juicio de los autores, todo lo arriba expresado se puede condensar en dos pensamientos" (Ciencia y desarrollo, № 154, 2000, 26).

de acuerdo con, según tal o cual persona, según la definición, a juicio de, en autores como, etc.

En la superficie del texto científico la intertextualidad dispone de un conjunto de marcadores capaces a identificar el conocimiento prestado (viejo) dentro del conocimiento científico nuevo. Su función es definir y hacer explícitas las «costuras» entre el estrato del conocimiento nuevo y el estrato del conocimiento viejo y precedente, o sea entre el texto portador y el texto prestado. 
Los marcadores discursivos del conocimiento viejo son: de acuerdo con, según tal o cual persona, según la definición, a juicio de, en autores como, etc. :

"A juicio de los autores, todo lo arriba expresado se puede condensar en dos pensamientos” (Ciencia y desarrollo, № 154, 2000, p. 26).

Es un fragmento fuente literal sin reducciones en el sentido conceptual completo implantado en el texto receptor. Es un fragmento comillado del texto reproducido exactamente del pre-texto. Por ejemplo:

«En este momento queremos hacer moldes poliméricos, que implica usar ceras líquidas, pero tenemos problemas por la contracción de cera"- explica Kohl» (Interciencia 2003. VII, №6).

«Es importante conocer los preceptos que indica el profesor Karl Terzaghi, pionero de mecánica de suelos y de problemas en campo: "Entender los fenómenos de naturaleza es una tarea difícil que el ingeniero cientifico tiene que descubrir sin desesperación"» (Ingeniería. Investigación y Tecnología. V. I, № 5, 2000).

«Ya calculadas las tendencias preferenciales delflujo-dice la licenciada de Intevep-se pueden ajustar las tasas de inyección y producción para mejorar la eficiencia del barrido» (Petróleo Internacional, junio, 2001).

Las palabras prestadas pueden están ensertadas dentro del citador.

La cita reducida es un fragmento reducido cuyo sentido conceptual lógicamente se inserta en el contexto del texto receptor. Sus rasgos diferenciales principales también tienen la marcación explícita del préstamo, pero la cita está reducida y las construcciones sintácticas están sin incluir las palabras de introducción del autor. Por ejemplo:

"La ingeniería inversa "es el acto de crear un conjunto de especificaciones para sistemas hardware por medio del análisis y dimensionamiento de un espécimen» (Ingeniería. Ciencias ambientales, №44, 1999).

"La ingeniería inversa es "una herramienta para actualizar la base de datos $C A D »$ (Ingeniería. Ciencias ambientales, №44, 1999).

La cita reproduce literalmente el fragmento prestado el cual tiene marcadores explícitos con la referencia obligatoria de la página del texto de la fuente.

La cita segmentada representa segmentos citados con los intervalos pequeños y con los marcadores explícitos del préstamo que tiene las estructuras conceptuales dentro el texto «ajeno». En la cita hay préstamos segmentados y las construcciones sintácticas tambien están sin incluir las palabras de introducción del autor:

Se habla del «efecto restaurador de la naturaleza» que permite a las personas «limpiar la cabeza, recuperar la dirección de la atención....” (Interciencia. Revista de ciencia y tecnología de América Latina, v. 30, № 11, 2005).

El estilo indirecto o en otro término la "cita indirecta" a diferencia de la cita completa se somete a la transformación considerable del contenido y «satura» las fronteras en el texto portador. La construcción sintáctica del estilo indirecto avanza al investigador quien analiza o interpreta las palabras ajenas con los marcadores formales intertertextuales. El estilo indirecto tiene modelos sintácticos para indicar a los citadores que tienen las estructuras conceptuales dentro el texto «ajeno». Los marcadores intertextuales del estilo indirecto no tienen comillas. Por ejemplo:

"Lynd (1996) señala que en este caso no se requiere dedicar gastos de capital o de operación para la producción de enzimas dentro del proceso» (Interciencia, 2005, vol. $30 \mathrm{~N}^{\circ} 11$ );

"Rekoff enfatiza la necesidad de entender el funcionamiento» (Ingeniería. Ciencias ambientales, №44, 1999); 
«Aranson ha descrito algunos productos comerciales» (Ingeniería. Ciencias ambientales, №44, 1999). El estilo indirecto no reproduce las palabras ajenas sino el concepto ajeno.

Los marcadores intertextuales tienen la introducción e intercalaciones, los marcadores léxicos, léxico-sintácticos con los verbos de hablar, declarar, señalar, enfatizar, de acuerdo con, según, en palabras de, etc.

«De acuerdo con Rekoff, la estrategia general de la ingeniería inversa es tomar un producto» (Ingeniería. Ciencias ambientales, №44, 1999).

«A juicio de los autores, todo lo arriba expresado se puede condensar en dos pensamientos» (Ciencia y desarrollo, № 154, 2000).

Cabe mencionar que las construcciones estructurales del estilo indirecto son más frecuentes que las citaciones en los textos científico-técnicos. Además los marcadores intertextuales del estilo indirecto son implícitos mientras que los marcadores de citación son explícitos.

La referencia intertextual se determina como un tipo de la relación intertextual en el cual no se integra el fragmento del texto sino se remite al conocimiento del fondo presentado implícitamente. La cantidad de estas referencias cognitivas supera considerablemente la cantidad de las citas completas o indirectas en los textos científicos. Las referencias cognitivas existen para formarelespaciodel fondoteórico precedente, para poder actualizar el pretexto para la percepción en caso necesario. Estos conocimientos precedentes subyacen en el espacio del texto nuevo en los esquemas evocados. La predominancia de las referencias se debe a los procesos informativos de compactación y compresión en el conocimiento científico.

Los rasgos formales de las referencias que existen dentro del texto receptor remiten a la bibliografía en su título, el nombre y el apellido del autor y otros datos bibliográficos. En el texto receptor a menudo dejan entre paréntesis sólo el nombre y el año:

«Las aplicaciones notificadas de estos métodos han aumentado en años recientes» (Evans, 1991; Hosni et.al., 1993; Motavalli y Shamsaasef, 1994; Mirloy et al., 1996).

«Además son de los pocos métodos prácticos que ofrecen información acerca del origen, disponibilidad física-química y biológica, movilización y transporte de metales pesados en ambientes acuáticos» (Tessier y Camfbell, 1987; Kersteny Forstner,1991; Hriwitz, 1991; Landing y Lewis, 1991; Lewis y Landing, 1992; Martínez y Senior, 2001).

Actualmente en los textos científico-técnicos hay una gran cantidad de las referencias:

«Los datos disponibles de estrategia (De Cserna Zoltán, et. al., 1988; Delgado Grabados, et. al, 1994) paleomagnetismo (Centeno Elena, et. al, 1986), arqueología y vegetación (Rzadovski, 1954), composición litológica (Badilla Cruz, 1977, Martín del Pozo, 1982) $y$ edades radiométricas (Urrutia Fucugauchi, 1996) de la zona conocida como "pedregal de San Angel" han contribuido a la caracterización de un evento volcánico reciente de la cuenca de México». (Ingeniería. Investigación y Tecnología, v. 1, № 5, 2000). En este caso en las relaciones intertextuales se desarrollan los conocimientos viejos compactados.

Las intercalaciones inglesas. Las relaciones intertextuales de la lengua española se vinculan con las intercalaciones de inglés. Por ejemplo:

«Es la versión original del artículo

"Concepts and Term Hierarchy", que se publicó en la revista Terminology, International Journal of Theoretical and Applied Issues en Specialized Communication" (Interciencia, 2005, vol. $30 \mathrm{~N}^{\circ}$ ). El artículo y la revista de español están escritos en inglés sin traducción del español. 
Se encuentran las intercalaciones inglesas con la traducción del español:

«Esta frgmentación de la molécula principal se conoce como "craking pattern", o fragmentación, que será el término utilizado en este trabajo» (Interciencia, 2001, vol. 30 № 10).

«Straggling: Fenómeno de dispersión de energía de las partículas incidentes (en principio mono-energéticas), al interaccionar con la muestra» (Interciencia, 2001, vol. 30 № 10).

También se observan las siglas con las intercalaciones inglesas en la textura del texto español. Por ejemplo:

$« D A E$. Posc Data Store Application Program Interface. Estáúnicomuyestrechamente con el Epicentro, en él se encuentran las especificaciones de como pueden acceder al PDS (Posc Data Store) las aplicaciones, a través de un $A P I »$ (Ingeniería. Investigación y Tecnología.1.4. 2000).

«Los estándares en cuestión son los siguientes: POSCPetrotechnicalOpen Sodftware Corporation (Corporación petrotécnica de sistemas abiertos)» (Ingeniería. Investigación y Tecnología.1.4. 2000).

También se observan las siglas inglesas con la traducción española. Por ejemplo:

«Es la implementación y desarrollo de la sacarificación y fermentación simultáneas (SSF por sus siglas en inglés)» (Interciencia, 2001, vol. $30 \mathrm{~N}^{\mathrm{o}} 12$ ).

También se observan en los textos científicos las intercalaciones terminológicas de la lengua latina. Por ejemplo:

«Se han desarrollado cepas de S. Cerevisiae a las cuales se les ha introducido un plásmido que le confiere la capacidad de expresar los genes que codifican la ámilasa de la bacteria Bacillus subtilis y la glucoamilasa del hongo Aspergillus awamori, adquiriendo asi la habilidad deconvertir directamente el almidón en EtOH» (Interciencia, 2001, vol. 30 № 10).
Cabe mencionar que el conocimiento viejo refleja la continuidad y representa el mecanismo de la intertextualidad.

\section{Subtexto precedente}

El subtexto precedente representa un signo personal «ajeno» de «cuantos» del conocimiento viejo. El subtexto precedente como un bloque conceptual tiene un valor especial conocido para un determinado grupo de investigadores que dominan el conocimiento científico común para los investigadores. En el texto científico-técnico se distinguen los epónimos científicos, en que se indican las funciones de autoridad de su autor y la función de la compresión de la información.

Los términos epónimos están personificados y están relacionados con el nombre del investigador y su concepción que páulatinamente va convirtiéndose en un signo del conocimiento científico. Por ejemplo, la raíz de "galvan" (investigador L.Galván) forma los términos de galvanismo, galvanizar, galvanización, galvanómetro, galvanoplastia, galvanotecnia. La raíz "pasteur" (investigador L. Pasteur), forma los términos pasteurela, pasteuriza, pasteurización. La raíz "hipnos"( Hipnos, dios del sueño) forma los términos hypnosis hipnosia, hipnosis, hipnotizable, hipnótico, hipnofobia, hipnogenesis).

Es un conocimiento viejo cuyo contenido está reducido al término o concepto muy bien conocido en la ciencia y en la cultura que por lo tanto no necesita desciframiento. En el aspecto cognitivo el subtexto precedente es el procedimiento de compresión del conocimiento viejo para conservar, compactar y acumularlo.

El subtexto precedente representa la compresióndelconocimientoviejo.Confrecuencia se encuentran los epónimos de los nombres de los investigadores que realizaron un descubrimiento: caracol de Pascal, célula de Jordan, cortadura de Dedekind, criba de Eratóstenes, integral 
de Riemann, ley de Boltzmann, onda de Lamb, onda de Love, frontera de Conrad, dispositivo de Schlumberger, efecto Compton. Los términos de adjetivos formados de nombres personales son: de Euclides - euclidiano, de Euler - de euleriano, de Tauber - tauberiano, de Newton - newtoniano, pitagórico; (véase, la concepción saussureana y hjelmsleviana, el relativismo whorfiano, postulado chomskyano). Por ejemplo, el subtexto precedente que representa «el efecto Compton» en forma compactada. «El efecto Compton consiste en el aumento de la longitud de onda de un fotón de rayos $\mathrm{X}$ cuando choca con un electrón libre y pierde parte de su energía. La frecuencia o la longitud de onda de la radiación dispersada depende únicamente de la dirección de dispersión. Como consecuencia de estos estudios Compton ganó el Premio Nobel de Física en 1927 (Wikipedia)».

Estos conceptos son la herramienta de la compresión del conocimiento precedente que permite conectar las relaciones intertextuales con una u otra concepción, criterios, espacios, algoritmos, analogías, etc.. La compresión del conocimiento precedente permite actualizar las relaciones intertextuales por medio de las estructuras determinadas.
Los más frecuentes son los subtextos precedentes de las estructuras sintácticas de "subjuntivo+nombre personal": frontera de Mohorovicic, zona de Benioff, onda de Stoneley, etc. Menos frecuentes son los complejos terminológicos con las estructuras sintácticas de "subjuntivo+ sustantivo + nombre personal" ; "subjuntivo+ adjetivo + nombre personal", etc.: potencial de ondas de Rayleigh, ecuación de Voigt para ondas, anomalía gravitacional de Bouguer, anomalía gravitacional de Fay.

La función principal de los marcadores discursivos del conocimiento precedente consiste en cambiar las construcciones largas en vez que las fórmulas cortas, acumulando de esta manera el conocimiento precedente. Estos marcadores no tienen comillas.

El subtexto del conocimiento viejo y el subtexto precedente forman parte de la estructura conceptual del texto científico y representan la continuidad, carácter dialógico e intertextualidad así como «encajan» el nuevo conocimiento «sumergido» en el contexto cognitivo, axiológico, pragmático, etc.. La función principal de los epónimos formados de los nombres de los investigadores anteriores consiste en cambiar las construcciones largas en vez de las

Cuadro 1. Correlación entre los destintos aspectos del conocimiento, su autorización con distintos tipos de autores, distintos tipos de relaciones intertextuales y su carácter de manifestación verbal.

\begin{tabular}{|l|l|l|l|}
\hline \multicolumn{1}{|c|}{ conocimiento } & \multicolumn{1}{|c|}{ autorización } & $\begin{array}{c}\text { tipos de relaciones } \\
\text { intertextuales }\end{array}$ & \multicolumn{1}{|c|}{ manifestación verbal } \\
\hline $\begin{array}{l}\text { conocimiento } \\
\text { nuevo }\end{array}$ & autor del texto nuevo & $\begin{array}{l}\text { recursos verbales de } \\
\text { estereotipos textuales }\end{array}$ & marcadores explícitos \\
\hline conocimiento viejo & $\begin{array}{l}\text { autores citadores del texto viejo } \\
\text { autores referenciadores } \\
\text { del texto viejo }\end{array}$ & $\begin{array}{l}\text { citas completas } \\
\text { citas reducidas } \\
\text { citas indirectas } \\
\text { referencias cognitivas }\end{array}$ & $\begin{array}{l}\text { marcadores explícitos } \\
\text { marcadores implícitos }\end{array}$ \\
\hline $\begin{array}{l}\text { conocimiento } \\
\text { precedente }\end{array}$ & $\begin{array}{l}\text { autor precedente de alto } \\
\text { prestigio (del signo personal) }\end{array}$ & citas - términos & $\begin{array}{l}\text { intercalaciones con marcadores } \\
\text { (comillas) } \\
\text { intercalaciones sin marcadores }\end{array}$ \\
\hline $\begin{array}{l}\text { conocimiento del } \\
\text { fondo común para } \\
\text { los investigadores }\end{array}$ & $\begin{array}{l}\text { el cuadro científico del mundo } \\
\text { de los investigadores en un } \\
\text { área determinada }\end{array}$ & $\begin{array}{l}\text { patrimonio científico } \\
\text { cultural }\end{array}$ & $\begin{array}{l}\text { Desaparición de marcadores, } \\
\text { conocimiento científico común }\end{array}$ \\
\hline
\end{tabular}


fórmulas cortas, acumulando de esta manera el conocimiento precedente. Estos marcadores no tienen comillas.

\section{Conclusiones}

Es conveniente puntualizar las siguientes conclusiones: la integración de los subtextos del conocimiento nuevo, viejo y del conocimiento precedente en la estructura intertextual representa un vehículo universal de la intertextualidad del texto científico-técnico.

Para concluir vamos a resumir en forma de tabla la correlación entre los destintos aspectos del conocimiento, su autorización con distintos tipos de autores, distintos tipos de relaciones intertextuales y su carácter de manifestación verbal.

\section{Referencias bibliográficas}

Bakhtin, M. (1979). Estetika slovesnogo tvorchestva [The Aesthetics of Verbal Creativity]. Moscow, Progress, 423 p.

Barthes, R. (1989). Semiotika. Poetika. [Semiotics. Poetics]. Moscow, Progress, 616 p.

Dolzhich, E.A., Popova, T.G. (2012). Intertekstual'nye sviazi v ispanskom nauchnom diskurse [Intertextuality in Spanish Scientific Discourse]. Moscow, RUDN, 169 p.

Kristeva, J. (1967). Sémiotiké: Recherches pour une sémanalyse. Paris.

Popova, T.G. (2003). Ispanskii nauchno-tekhnicheskii tekst: traditsii i sovremennye podkhody $k$ izucheniiu [Scientific and Technical Texts in Spanish: Current and Traditional Approaches to the Study]. Moscow, RUDN, 160 p.

\section{Вербализация знаний в испанском научно-техническом тексте}

\section{Т.Г. Попова}

Российский университет дружбы народов Россия, 115419, Москва, ул. Орджоникидзе, 3

\footnotetext{
Интеграция нового, старого и прецедентного знания определяется универсальным построением научного текста. Новое знание, вербализированное на плоскости текста, представляет собой развернутую композиционную речевую структуру, репрезентируюшую предметное содержание полученного знания. Вербализированное новое знание является смысловым стержнем всего текста в его основных фазах - проблемы, идеи, гипотезы, доказательства, вывода. Старое знание возникает на пересечении двух контекстов - «своего» и «чужого». Старое знание демонстрирует истории вопроса, способы решения научной проблемы, выражает связь с предшествующими концепциями, эксплицирует принадлежность автора к той или иной научной школе, воспроизводит чужое высказывание. Типь текстовой репрезентации старого знания определяются когнитивными и коммуникативными функииями. Вербальными маркерами ввода старого знания служат глаголь речи и мысли для чужого высказывания.

Прецедентное знание можно рассматривать как один из механизмов формирования и сохранения научной традици. Эти не просто знаки целых текстов, которым они эквивалентны по смыслу, а значимые личностные знаки, на что указывают содержащиеся в них антропонимы. Появление прецедентных контекстов в научных публикациях свидетельствует об антропоморфизачии и персонификации науки, т.е. имя ученого - субъекта прецедента - в какой-то момент начинает отождествляться с его конщепџиией, входит в “золотой фонд” науки и ста-
} 
новится знаком самого научного знания. В гносеологическом плане прецедент является типичным приемом сжатия старого знания с целью его сохранения, уплотнения и дальнейшего научного накопления.

Ключевые слова: интертекстуальность, научный текст, дискурс, новое знание, старое знание, прецедентное здание, дискурсивные маркеры.

Научная специиальность: 10.00.00 - филологические науки. 